(C) 2021, The Authors. Published by Elsevier Inc. and Fass Inc. on behalf of the American Dairy Science Association ${ }^{\circledR}$. This is an open access article under the CC BY-NC-ND license (http://creativecommons.org/licenses/by-nc-nd/4.0/).

\title{
The effect of Cryptosporidium parvum, rotavirus, and coronavirus infection on the health and performance of male dairy calves
}

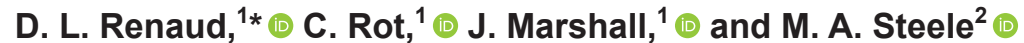 \\ ${ }^{1}$ Department of Population Medicine, University of Guelph, Ontario N1G 2W1, Canada \\ ${ }^{2}$ Department of Animal Biosciences, University of Guelph, Ontario N1G 2W1, Canada
}

\begin{abstract}
The objective of this prospective cohort study was to investigate the effect of bovine coronavirus (BCoV), bovine rotavirus (BRoV), and Cryptosporidium parvum on dairy calf health and performance and to determine the prevalence of these pathogens. A total of 198 male dairy calves housed at a grain-fed veal facility were examined from June 11, 2018, to October 9, 2018. Calves were fed milk replacer twice daily and housed individually until weaning at $56 \mathrm{~d}$. Once weaned, calves were moved into groups of 5 until they were moved to a finishing facility at $77 \mathrm{~d}$. At the grain-fed veal facility, calves were scored for fecal consistency for the first $28 \mathrm{~d}$ and had fecal samples taken on arrival and at 7 and $14 \mathrm{~d}$. Fecal samples were frozen and submitted to a commercial laboratory, where they were tested for $\mathrm{BCoV}$, C. parvum, and 2 groups of BRoV: group A (BRoV A) and group B (BRoV B). Calves were weighed on arrival and at 14, 49, 56, and $77 \mathrm{~d}$ using a digital body scale. Treatments for disease and mortalities that occurred over the $77 \mathrm{~d}$ were also recorded. Statistical models, including Cox proportional hazards and repeated measures models, were built to determine the effect of infection with 1 of the pathogens. Over the 3 sampling points, 151 (85.8\%), 178 (94.2\%), 3 (1.5\%), and $97(57.4 \%)$ calves tested positive at least once for $\mathrm{BCoV}, \mathrm{BRoV} \mathrm{A}, \mathrm{BRoV} \mathrm{B}$, and C. parvum, respectively. The source of the calves and the level of serum total protein measured on arrival were associated with testing positive for a pathogen. Calves that tested positive for C. parvum had an increased proportion of days with diarrhea and severe diarrhea; calves that tested positive for $\mathrm{BCoV}$ and $\mathrm{BRoV} \mathrm{A}$ had an increased proportion of days with severe diarrhea. In addition, calves that tested positive for C. parvum had a higher hazard of being treated for respiratory disease. With respect to body weight, calves that had diarrhea or severe
\end{abstract}

Received July 4, 2020.

Accepted September 25, 2020.

*Corresponding author: renaudd@uoguelph.ca diarrhea had lower body weight at 49, 56, and $77 \mathrm{~d}$. Specifically, calves that had an increased proportion of days with diarrhea showed a reduction in weight gain of up to $15 \mathrm{~kg}$ compared to calves without diarrhea. Calves that tested positive for C. parvum had a lower body weight at 49,56 , and $77 \mathrm{~d}$; calves that tested positive for $\mathrm{BCoV}$ had a lower body weight at 56 and $77 \mathrm{~d}$. This study demonstrates that the prevalence of $\mathrm{BCoV}, \mathrm{BRoV} \mathrm{A}$, and C. parvum infection is high in this population of calves and has significant effects on the occurrence of diarrhea and body weight gain. Future studies should evaluate approaches for minimizing the effect of infection with these pathogens to improve the welfare, health, and productivity of dairy calves.

Key words: dairy calf, diarrhea, disease

\section{INTRODUCTION}

Diarrhea is a disease that occurs commonly in the dairy and veal industries; 23 and $42 \%$ of female and male dairy calves, respectively, are treated for diarrhea (Windeyer et al., 2014; Scott et al., 2019). This disease has substantial effects in dairy calves, leading to increased mortality, reduced growth (Pardon et al., 2013; Windeyer et al., 2014), and in female calves, a negative effect on age at first calving and future milk production (Waltner-Toews et al., 1986a; Svensson and Hultgren, 2008). Because of these consequences, it is estimated that the annual cost of diarrhea is between US $\$ 33$ and $\$ 36$ per preweaned calf (Kaneene and Hurd, 1990; Roche et al., 2020). Bovine rotavirus (BRoV), bovine coronavirus (BCoV), and Cryptosporidium parvum are recognized globally as endemic in cattle and are among the most predominant causes of diarrhea in the dairy industry (Nydam and Mohammed, 2005; Papp et al., 2013; Gomez and Weese, 2017). Calves are at highest risk of acquiring these pathogens in the first month of age, when they are exposed via a fecal-oral route to highly concentrated pathogens in the surrounding environment (Nydam and Mohammed, 2005).

The prevalence of these pathogens in dairy calves has not been well explored in recent literature in Canada. 
On 78 dairy farms from a 1986 study completed in southwestern Ontario, the prevalence of $\mathrm{BCoV}$ was $5.4 \%$ and the prevalence of BRoV was $18.6 \%$ (Waltner-Toews et al., 1986b); however, because testing procedures have changed substantially, this finding is likely no longer relevant. A study completed on 6 dairy farms between 2014 and 2016 explored only $\mathrm{BCoV}$ and found that $55 \%$ of calves $(157 / 286)$ sampled at a single time point were positive for this pathogen (Gomez et al., 2017). The prevalence of $C$. parvum has not been investigated in over a decade. The most recent study, performed in 2004, was done on 119 dairy farms in southern Ontario and found that $30 \%$ of calves $(327 / 1,089)$ were shedding C. parvum oocysts, and at least 1 calf tested positive in $77 \%$ of the herds (Trotz-Williams et al., 2008). At present, the prevalence of these 3 pathogens is unknown in veal production, and because veal farms rely on the purchase of calves from dairy farms, the prevalence of $\mathrm{BCoV}, \mathrm{BRoV}$, and C. parvum at veal facilities may serve as a sentinel for current levels on dairy farms.

As well, very little research has been conducted to investigate the associated production effects of $\mathrm{BCoV}$, $\mathrm{BRoV}$, or C. parvum infection in calves. Each of the pathogens has been associated with a higher occurrence of diarrhea (Trotz-Williams et al., 2007; Gomez et al., 2017). However, the longer-term effects of infection from each respective pathogen in calves are not well understood (Thomson et al., 2017). Because of the multifactorial nature of diarrhea, more research is necessary to investigate the effects of these enteric pathogens on productivity and health in dairy calves.

The objective of this prospective cohort study was to investigate the effect of $\mathrm{BCoV}, \mathrm{BRoV}$, and C. parvum on calf health and performance and determine the prevalence of these pathogens in male dairy calves. A secondary objective was to evaluate the associations between factors measured on arrival at the veal facility and the prevalence of infection with these diarrheacausing pathogens. We hypothesized that infection with 1 or more of these pathogens at any point in the first month of life would lead to an increased risk of diarrhea and respiratory disease, and to reduced growth.

\section{MATERIALS AND METHODS}

\section{Study Design}

We conducted this single prospective cohort study at a commercial grain-fed veal calf facility within $50 \mathrm{~km}$ of Guelph, Ontario, Canada. The participating farm was selected for convenience, location, and previous association with the Ontario Veterinary College (Guelph, ON, Canada). Animal use in this study was approved by the University of Guelph Animal Care Committee (Animal Use Protocol \#3850). A total of 198 male dairy calves housed in 3 rooms were used in this study and examined over a 6-mo period. We did not conduct a formal sample size calculation; the sample size was based on resource limitations. Data were collected on farm between June 11, 2018, and October 9, 2018.

\section{Animal Housing, Management, and Enrollment}

All calves that arrived at the facility between June 11 and July 26, 2018, were eligible for enrollment. The calves were brought to the rearing facility at approximately 3 to $7 \mathrm{~d}$ of age from dairy farms and drovers in Ontario. The calves in this study were all male Holstein dairy calves, and they were evaluated for $77 \mathrm{~d}$; measurements of health and growth were recorded throughout the study period by a single trained research technician. The facility housed the calves individually in $1-\mathrm{m}^{2}$ stalls for the first $49 \mathrm{~d}$ on arrival, where they could have physical contact with the calves housed immediately beside them. After weaning, calves were transitioned into groups of 5 . The calves were fed $26 \%$ protein and 17\% fat milk replacer (Mapleview Agri Ltd., Mapleton, ON, Canada) on the following schedule: $260 \mathrm{~g}$ in $2 \mathrm{~L}$ twice daily for wk 1 to $2 ; 325 \mathrm{~g}$ in $2.5 \mathrm{~L}$ twice daily for wk 3; $450 \mathrm{~g}$ in $3 \mathrm{~L}$ twice daily for wk 4 to $5 ; 450 \mathrm{~g}$ in $3 \mathrm{~L}$ once daily for wk 6 ; and $450 \mathrm{~g}$ in $3 \mathrm{~L}$ every third feeding for wk 7 . Free access to water and grain was provided to the calves for the entire period. The grain offered was texturized calf starter $(18 \% \mathrm{CP})$ on arrival until wk 3 , at which point calves were transitioned to a corn and pellet ration with $2 \%$ straw $(18.1 \% \mathrm{CP})$ for the remainder of the experimental period.

\section{Data Collection}

On arrival, calves were evaluated for passive immunity status. Blood was collected from jugular venipuncture using a 20-gauge, 1-inch needle (BD Vacutainer Needles; Becton, Dickinson and Co., Franklin Lakes, NJ) into a $10-\mathrm{mL}$ serum vacuum tube without anticoagulant (BD Vacutainer Serum Blood Collection Tubes; Becton, Dickinson and Co.). These blood samples were chilled within minutes of collection in a cooler with ice packs. The $10 \mathrm{~mL}$ blood samples were centrifuged at $1,500 \times g$ for 10 min within $5 \mathrm{~h}$ of collection, followed by storage in a refrigerator at $4^{\circ} \mathrm{C}$ for serum total protein (STP) analysis within $12 \mathrm{~h}$ of collection. Stored serum samples were transferred to an optical refractometer (RHC-200ATC; SinoTech, Fujian, China) using a new disposable pipette for each sample. The STP values were visually determined, and results were recorded 
first on paper and then entered into a spreadsheet. A STP level of $<5.1 \mathrm{~g} / \mathrm{dL}$ was used as the cutoff for determining the presence of failed transfer of passive immunity (FTPI; Renaud et al., 2018a). Calves were also weighed on arrival using a digital weigh scale (TruTest, Mineral Wells, TX) and were weighed again at 14, 49,56 , and $77 \mathrm{~d}$ after arrival to assess growth.

Fecal consistency was scored daily for the first 28 $\mathrm{d}$ after arrival. Guidelines to assess the fluidity of the calf's feces were based on subjective observations; increasing water content of the feces correlated with an increasing numeric fecal score. Fecal consistency scores used a 0- to 3-point scale based on McGuirk (2008). Normal, fully formed feces received a fecal score of 0 ; semi-formed and pasty feces received a fecal score of 1 ; loose feces received a fecal score of 2 ; and watery feces that sifted through the bedding received a fecal score of 3 . Calves with a fecal score of 2 or 3 were classified as having diarrhea (McGuirk, 2008); calves with a fecal score of 3 were classified has having severe diarrhea.

Fecal samples were collected into sterile containers; calves defecated after manual stimulation of the rectum on the day of arrival at the facility and at 7 and $14 \mathrm{~d}$ after arrival. Samples were stored at $-20^{\circ} \mathrm{C}$ until submission to a commercial laboratory (Animal Health Laboratory, Guelph, ON, Canada) for testing. Using real-time PCR testing, fecal samples were analyzed for $\mathrm{BCoV}$ and BRoV. Specifically, each fecal sample was swabbed and resuspended in PBS to make a $10 \%$ suspension. The suspension was vortexed and centrifuged before extraction. All samples were extracted using the MagNA Pure 96 (Roche, Mississauga, ON, Canada) and the PCR was run on the Light Cycler 480 (Roche). Levels of C. parvum were determined using sucrose wet mounts. Briefly, a thin preparation was made by mixing a drop of liquid feces with 2 or 3 drops of saturated sucrose solution on a slide, which was then covered with a coverslip and examined using light microscopy (Nikon, Minato City, Japan) after 3 to 5 min. Using high-dry magnification (40× objective), oocysts with a pink hue due to light refraction were counted and reported as semiquantitative results.

Calves were also scored for respiratory illness twice daily for the entire experimental period using a scoring system developed by Love et al. (2014). Briefly, the calf was evaluated for the presence of ocular discharge, nasal discharge, ear droop or head tilt, cough, rapid or difficult breathing, and elevated rectal temperature. If a calf had a score of 5 or greater, the calf was deemed to have bovine respiratory disease and was treated. Respiratory disease scores were not recorded systematically and could not be analyzed.
Group metaphylaxis was not administered at the time of arrival. Antimicrobial treatment and supportive therapy (non-steroidal anti-inflammatory medications and i.v. fluids) were recorded for each calf. Calves that experienced clinical disease were treated according to farm protocols. Oral meloxicam (meloxicam oral suspension, $10 \mathrm{~mL} / 150 \mathrm{~kg}$ p.o. once; Solvet, Calgary, AB, Canada) and a commercial electrolyte (Calf Lyte II, 76 g; Vetoquinol, Lavaltrie, QC, Canada) dissolved into $2 \mathrm{~L}$ of warm water were administered at the onset of a case of diarrhea. Oral electrolyte therapy continued once daily until the resolution of the diarrhea. If the diarrhea persisted for $2 \mathrm{~d}$, the oral meloxicam was continued and trimethoprim sulfadoxine (Borgal, $3 \mathrm{~mL} / 45$ kg i.m.; Merck Animal Health, Kirkland, QC, Canada) was administered for 3 consecutive days. Calves diagnosed with respiratory disease (score of $\geq 5$; Love et al., 2014) were treated with florfenicol (Nuflor, $6 \mathrm{~mL} / 45 \mathrm{~kg}$ s.c. once; Merck Animal Health) and injectable meloxicam (Metacam, $2.5 \mathrm{~mL} / 100 \mathrm{~kg}$ s.c. once; Boehringer Ingelheim, Burlington, ON, Canada).

\section{Statistical Analysis}

All statistical analyses were conducted in Stata 14 (StataCorp LP, College Station, TX). Data were imported from Excel (Microsoft, Redmond, WA) into Stata 14 and checked for completeness. Descriptive statistics were generated on all explanatory variables in the data set, using $t$ tests or Wilcoxon rank sum tests depending on normality for continuous variables and $\chi^{2}$ tests for categorical variables.

Several explanatory multivariable models were created to explore the variables contained within the data set. Repeated measure logistic regression models were constructed to identify factors of the arriving calf associated with higher levels of diarrheal causing pathogens. Repeated measure linear regression models were created to evaluate the effect of a pathogen and presence of diarrhea or severe diarrhea on weight measured at 14 , 49,56 , and $77 \mathrm{~d}$ after arrival. To evaluate the percent of days at risk of a fecal score $\geq 2$ or 3 , a generalized linear model with a logit link and binomial family was used. A Cox proportional hazard model was created to evaluate the effect that an infection with a diarrheal pathogen had on mortality, treatment for diarrhea, and treatment for pneumonia in the observation period. Two models were built for each of the outcomes, with the exception of factors of the arriving calf associated with higher levels of pathogens and models evaluating the effect of diarrhea or severe diarrhea on growth, to assess the effect of a positive test at each individual time point $(0 \mathrm{~d}, 7 \mathrm{~d}$, and $14 \mathrm{~d}$ after arrival) and the 
cumulative positive test result (i.e., positive at any of the time points).

The assumption of linearity of continuous variables was assessed in each model and if a variable failed to meet the linearity assumption, the variable was categorized. Collinearity among the explanatory variables was tested using Spearman rank coefficients and if the correlation coefficient between 2 variables was $\geq 0.7$, only one variable was retained based on biological plausibility. Univariable regression models were constructed to screen for variables that were unconditionally associated with the outcome using a liberal $P$-value of 0.2 . Risk factors that had univariate associations $(P<0.2)$ were subsequently offered to a multivariable model through a manual backward stepwise process. Evaluating the effect of the removed variables on the coefficients of the remaining variables was used to assess confounding. A variable was deemed to be a confounder if it was not an intervening variable and the coefficient of a significant variable in the model changed by at least $20 \%$. Twoway interactions were evaluated between biologically important variables and remained in the final models if significant $(P<0.05)$. In the repeated measures models, predictive margins were generated for each interaction term and evaluated using pairwise comparisons. Each model was assessed for model fit. Specifically, homoscedasticity and normality of the residuals and best linear unbiased predictions were evaluated graphically in linear regression models, Pearson and Deviance residuals were generated and evaluated in the logistic regression models, and the proportional hazards assumption was tested in the cox proportional hazards models (Dohoo et al., 2010). Outliers were identified and were explored to determine the characteristics of the observations that made them outliers and ensure data were not erroneous. If data were erroneous, the outlier was deleted; however, none of the outliers in the analyses were found to have erroneous data.

\section{RESULTS}

\section{Descriptive Statistics}

A total of 198 male dairy calves were assessed from June to October 2018. The calves arrived at the facility in 3 groups: 80 arrived in June, and the remainder arrived in July. The majority of calves were sourced from local dairy farms $(55.6 \%)$, purchased directly from farms within a $30 \mathrm{~km}$ radius of the calf facility. The remainder of the calves were sourced from drover 1 (18.2\%), who purchased calves from across southwestern Ontario, and drover $2(26.3 \%)$, who purchased calves from Ontario and Quebec. The mean $[ \pm$ standard deviation $(\mathbf{S D})]$
STP of the calves was $5.5 \pm 0.68 \mathrm{~g} / \mathrm{dL}$, with a range of 3.0 to $7.4 \mathrm{~g} / \mathrm{dL}$. Based on a cutoff of less than $5.1 \mathrm{~g} /$ dL, 25.1\% of calves had FTPI. At arrival, calves' mean weight was $47.3 \pm 4.1 \mathrm{~kg}$.

\section{Prevalence of BRoV, BCoV, and C. parvum}

The prevalence of $\mathrm{BCoV}, \mathrm{BRoV} \mathrm{A}, \mathrm{BRoV} \mathrm{B}$, and $C$. parvum on arrival and at 7 and $14 \mathrm{~d}$ is highlighted in Figure 1. Of the calves that were positive for a pathogen on arrival, $12(13.8 \%)$ were positive for both $\mathrm{BCoV}$ and BRoV A, $3(3.4 \%)$ were positive $\mathrm{BCoV}$ and C. parvum, and $4(4.6 \%)$ were positive for BRoV A and C. parvum. When tested again at $7 \mathrm{~d}$ after arrival, more calves tested positive for $\mathrm{BCoV}, \mathrm{BRoV} \mathrm{A}$, and C. parvum; however, no calves tested positive for BRoV B. Coinfections were also more common at $7 \mathrm{~d}$ : of the calves that tested positive for a pathogen, $37(20.7 \%)$ had $\mathrm{BCoV}$ and BRoV A; 11 (6.1\%) had $\mathrm{BCoV}$ and C. parvum; 25 (14.0\%) had BRoV A and C. parvum; and 30 (16.8\%) had all 3 pathogens. At $14 \mathrm{~d}$ after arrival, more calves again tested positive for $\mathrm{BCoV}$ and fewer were positive for BRoV A and C. parvum. With respect to coinfections, of the calves that were positive for a pathogen at $14 \mathrm{~d}, 41(26.6 \%)$ had $\mathrm{BCoV}$ and $\mathrm{BRoV} \mathrm{A} ; 12(7.8 \%)$ had $\mathrm{BCoV}$ and C. parvum; $5(3.2 \%)$ had BRoV A and C. parvum; and $9(5.8 \%)$ had all 3 pathogens. Over the 3 sampling points, 151 (85.8\%), 178 (94.2\%), 3 (1.5\%), and $97(57.4 \%)$ calves tested positive at least once for $\mathrm{BCoV}, \mathrm{BRoV} \mathrm{A}, \mathrm{BRoV} \mathrm{B}$, and C. parvum, respectively. Because the number of calves that tested positive for $\mathrm{BRoV} \mathrm{B}$ was low, we did not analyze this pathogen in depth.

On the day of sampling, the test results were compared with whether calves had diarrhea (Figure 2). On arrival and at $14 \mathrm{~d}$, a higher proportion of calves that tested positive for C. parvum had diarrhea than those that tested negative at those time points. We detected no difference in the presence of diarrhea between calves that tested positive for $\mathrm{BCoV}$. With respect to $\mathrm{BRoV}$ A, calves that tested positive on arrival had higher rates of diarrhea than those that were negative on arrival. However, at $14 \mathrm{~d}$, calves that tested negative for BRoV A had higher rates of diarrhea than those that tested positive.

Multivariable repeated-measures logistic regression models identified several parameters measured at arrival that were associated with the presence of infection with a diarrhea-causing pathogen. For $\mathrm{BCoV}$, the source of the calves and the level of STP were associated with infection. Specifically, for every $1 \mathrm{~g} / \mathrm{dL}$ increase in STP, the odds of BoCV infection was reduced by $35 \%$ [odds ratio (OR) $0.65 ; 95 \%$ confidence interval (CI) 


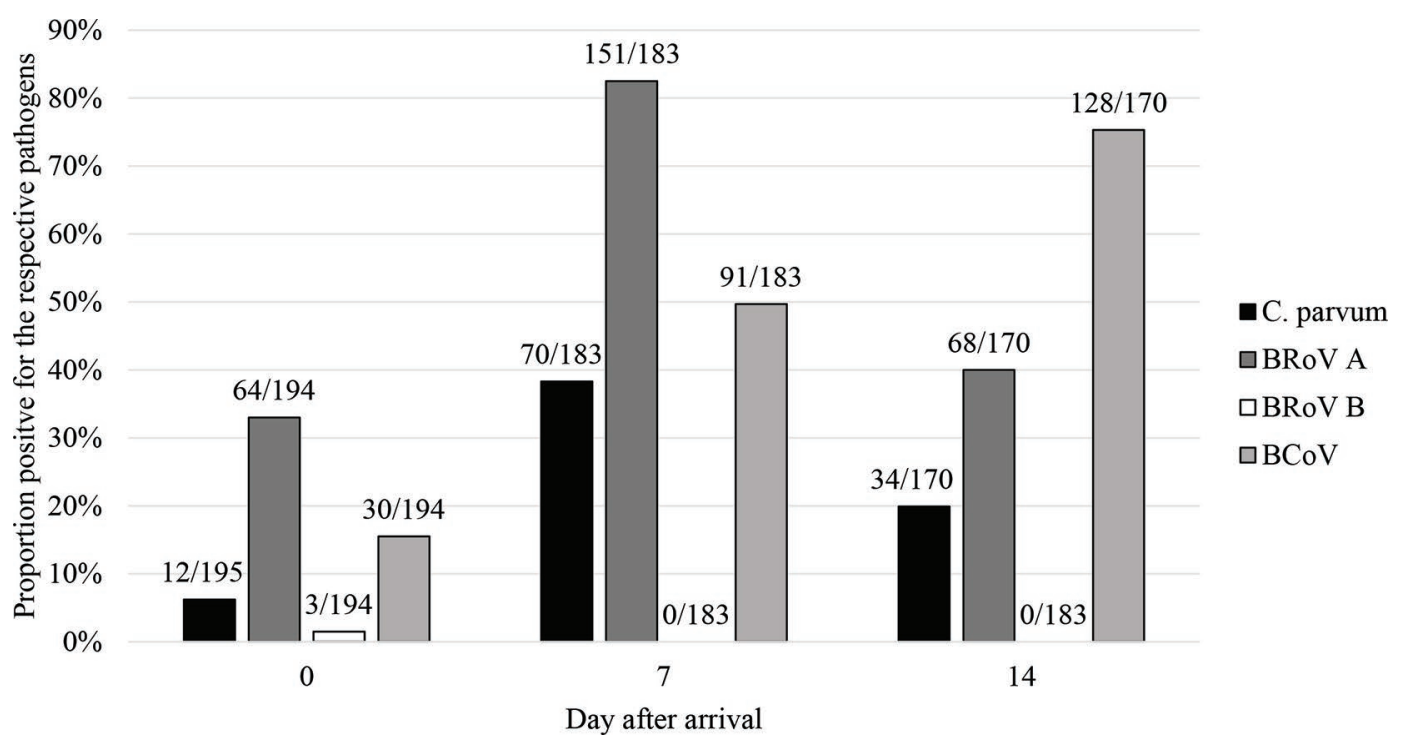

Figure 1. Prevalence of Cryptosporidium parvum, bovine rotavirus A (BRoV A), bovine rotavirus B (BRoV B), and bovine coronavirus $(\mathrm{BCoV})$ in feces collected from 198 male dairy calves at 0,7 , and $14 \mathrm{~d}$ after arrival at a grain-fed veal facility.

0.46 to $0.91 ; P=0.01]$. With respect to the source of the arriving calves, calves sourced from drover 2 had higher odds of being infected with $\mathrm{BCoV}$ over the 3 observation time points (OR 12.68, 95\% CI 4.47 to 35.99; $P<0.001)$ than calves sourced from local dairy farms. We found an interaction between the source of the calves and the sampling time; most of the increased probability of $\mathrm{BCoV}$ infection in calves from drover 2 occurred at arrival $(P<0.001)$ and $7 \mathrm{~d}$ after arrival $(P$ $<0.001$; Figure 3a) compared to locally sourced calves and calves from drover 1. Only the source of the calves was associated with the presence of $\mathrm{BRoV} A$ in the final model. Calves sourced from drover 2 had increased odds of being infected with BRoV A (OR 2.96, 95\% CI 1.41 to $6.20 ; P=0.004$ ) compared to locally sourced calves. However, similar to $\mathrm{BCoV}$, we found an interaction between the source of the calves and the sampling time: a higher number of calves sourced from drover 2 were infected at the time of arrival than locally sourced calves $(P=0.003)$ and calves from drover $1(P=0.04$; Figure $3 \mathrm{~b})$. An interaction term was also significant in a model evaluating $C$. parvum: rates of $C$. parvum infection were increased at $14 \mathrm{~d}$ in locally sourced calves $(P$ $=0.04 ;$ Figure $3 \mathrm{c})$.

\section{Treatment for Diarrhea}

The majority of the calves $(83.8 \% ; 166 / 198)$ were treated for clinical diarrhea (Figure 4a). When we evaluated the effect of calves testing positive at the different time points using univariable Cox proportional hazard analysis, we found no differences in the hazard for diarrhea treatment in calves that tested positive for $\mathrm{BCoV}, \mathrm{BRoV} \mathrm{A}$, or C. parvum on arrival or at 7 and $14 \mathrm{~d}$ compared to calves that tested negative at each time point. As well, in univariable analysis, we found no increase in the hazard for diarrhea treatment for calves that tested positive at any time point for $\mathrm{BCoV}$ [hazard ratio (HR) 1.09, 95\% CI 0.68 to $1.74 ; P=$ 0.73], BRoV A (HR 1.49, 95\% CI 0.73 to $3.03 ; P=$ 0.27 ), or C. parvum (HR $1.17,95 \%$ CI 0.84 to $1.64 ; P$ $=0.35$ ) compared to calves that tested negative at all 3 time points for each respective pathogen.

\section{Fecal Consistency Scoring}

Calves were identified as having diarrhea (fecal score of 2 or 3 ) for $33.3 \pm 14.2 \%$ (mean $\pm \mathrm{SD}$ ) of the $28 \mathrm{~d}$ under observation. For calves that tested positive for $\mathrm{BCoV}$ at any time point, the proportion of days they had diarrhea was $33.4 \pm 14.2 \%$, compared with $30.6 \pm$ $9.7 \%$ for those that tested negative at each sampling point $(P=0.29)$. The proportion of days with diarrhea for calves that tested positive for BRoV A was $33.8 \pm$ $14.6 \%$, compared to $29.3 \pm 8.1 \%$ for those that tested negative at each time point $(P=0.31)$. For $C$. parvum, calves that tested positive spent $34.2 \pm 13.3 \%$ of the $28 \mathrm{~d}$ under observation for diarrhea, and those that tested negative spent $29.4 \pm 11.1 \%$ of the time under observation $(P=0.02)$.

For the generalized linear model evaluating the presence of diarrhea (fecal score of 2 or 3 ) in calves that tested positive at specific time points, level of STP, BW on arrival, source of the calves, and test results 
for BRoV A on arrival and C. parvum at $14 \mathrm{~d}$ after arrival were offered to the multivariable model. In the final model, only $\mathrm{BW}$ on arrival and test results for C. parvum at $14 \mathrm{~d}$ were retained. Specifically, as BW on arrival increased by $1 \mathrm{~kg}$, the proportion of days with diarrhea decreased by $3 \%$ [relative proportion ratio (RPR) 0.97, 95\% CI 0.95 to $0.99 ; P=0.001$. Calves that tested positive for C. parvum at $14 \mathrm{~d}$ after arrival had a $24 \%$ increase in the proportion of days with diarrhea (RPR 1.24, 95\% CI 1.05 to $1.47 ; P=$ 0.01) compared to calves that did not test positive for C. parvum at $14 \mathrm{~d}$.

With respect to the generalized linear model evaluating the presence of diarrhea (fecal score of 2 or 3 ) and cumulative test results over the sampling time points, arrival weight, STP, source of the calves, and test results for BRoV A and C. parvum at any time point were offered to the multivariable model. Similar to the previous model, only BW on arrival and test results for C. parvum remained in the final model. For every $1 \mathrm{~kg}$ increase in BW at arrival, the proportion of days with diarrhea decreased by $3 \%$ (RPR 0.97, 95\%
CI 0.96 to $0.99 ; P=0.005)$. Calves that tested positive for $C$. parvum at any time point had a $23 \%$ increase in the proportion of days with diarrhea (RPR 1.23, 95\% CI 1.04 to $1.46 ; P=0.01$ ) compared with calves that tested negative at each time point.

We found severe diarrhea (fecal score of 3) in $12.8 \pm$ $12.9 \%$ (mean $\pm \mathrm{SD}$ ) of the days under observation. For calves that tested positive for $\mathrm{BCoV}$ at any time point, the proportion of days with severe diarrhea was $13.8 \pm$ $7.1 \%$, compared with $8.5 \pm 1.4 \%$ for those that tested negative at each time point $(P=0.06)$. The proportion of days with diarrhea for calves that tested positive for BRoV A was $13.3 \pm 13.1 \%$, compared with $7.1 \pm 4.9 \%$ for those that tested negative at each time point $(P=$ 0.09). For C. parvum, calves that tested positive spent $13.3 \pm 11.9 \%$ of the $28 \mathrm{~d}$ under observation for diarrhea, compared with $10.1 \pm 9.3 \%$ for those that tested negative $(P=0.05)$.

When evaluating each time point individually, source of the calves, FTPI status, BW on arrival, arrival group, and test results for $\mathrm{BCoV}$ at $7 \mathrm{~d}$, C. parvum at 7 $\mathrm{d}$, and BRoV A on arrival were offered to the multivari-
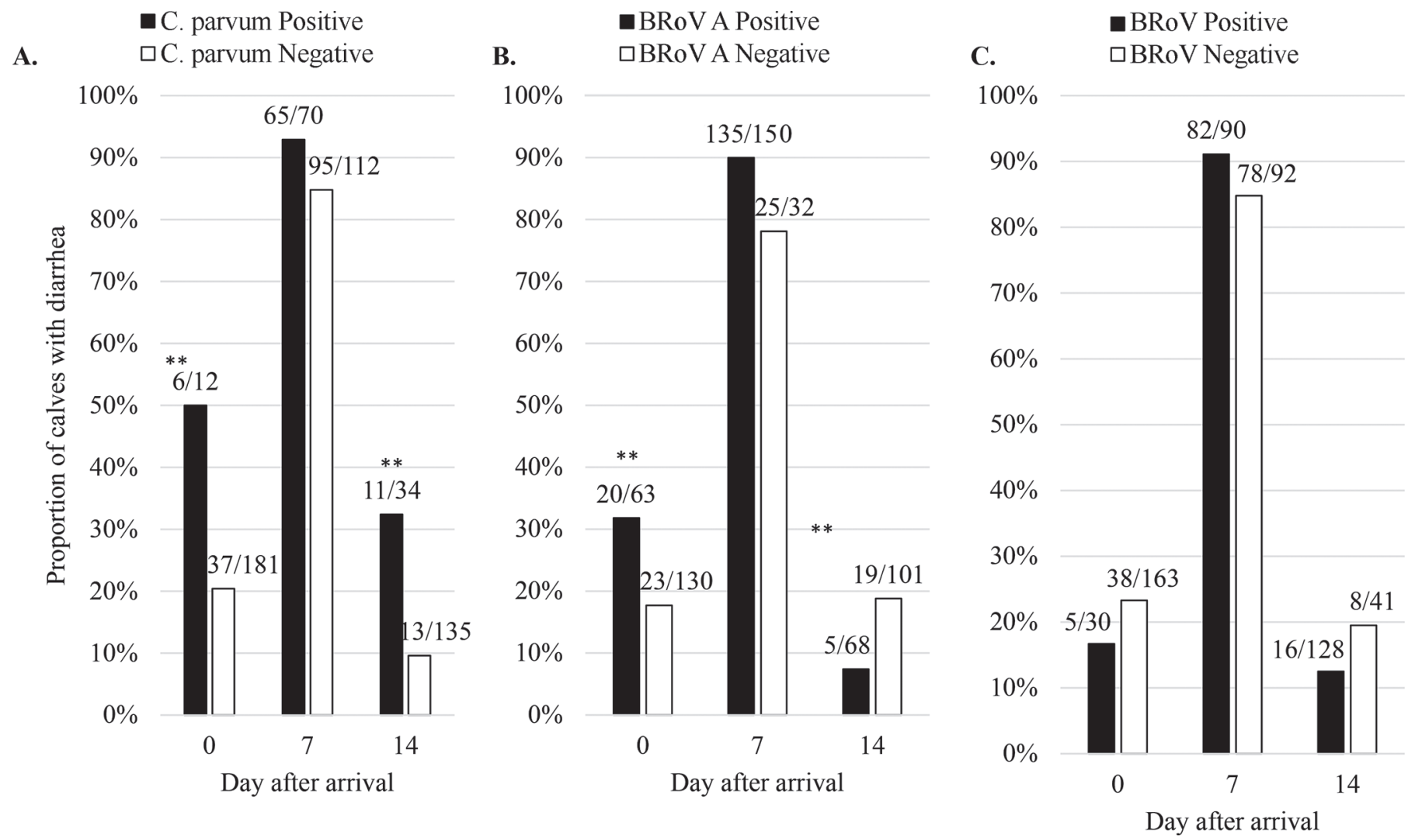

Figure 2. Prevalence of diarrhea (fecal score of 2 or 3) and presence of (A) Cryptosporidium parvum, (B) bovine rotavirus A (BRoV A), and $(\mathrm{C})$ bovine coronavirus (BCoV) from feces collected from 198 male dairy calves at 0,7 , and $14 \mathrm{~d}$ after arrival at a grain-fed veal facility. ** Significant finding $(P<0.05)$ between those that were positive and those that were negative for the pathogen $\left(\chi^{2}\right.$ test). 

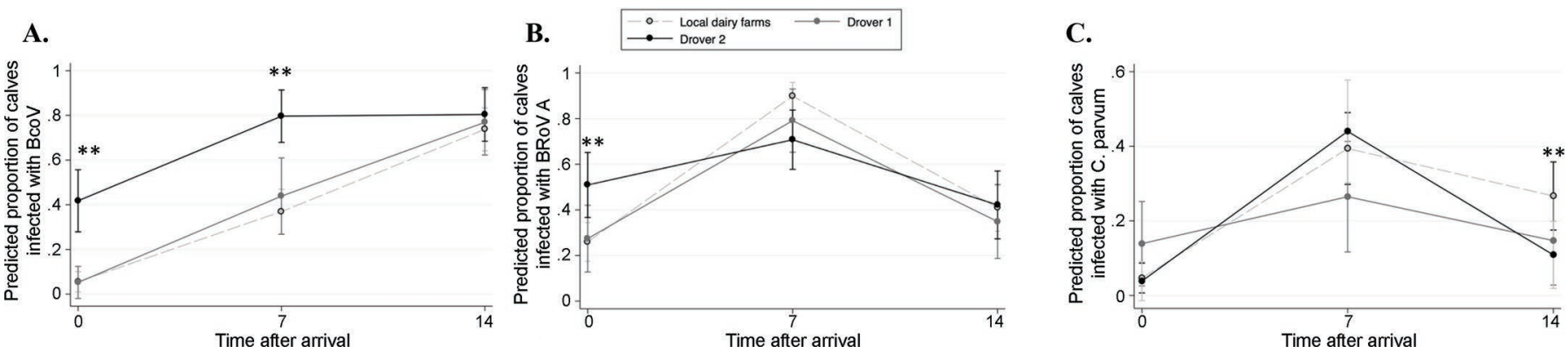

Figure 3. Predicted margin results from mixed logistic regression models evaluating an interaction term between the source of the calves and the presence of (A) bovine coronavirus (BCoV), (B) bovine rotavirus A (BRoV A), and (C) Cryptosporidium parvum from fecal samples collected from 198 male dairy calves at 0,7 , and $14 \mathrm{~d}$ after arrival at a grain-fed veal facility. ${ }^{* *}$ Significant finding $(P<0.05)$ between sources of calves.

able generalized linear model evaluating the presence of severe diarrhea (fecal score of 3). In the final model, only BW on arrival and source of the calves remained. Specifically, calves from drover 2 and those with a lower BW at arrival had a higher proportion of days with a fecal score of 3 (Table 1).

Test results for C. parvum, $\mathrm{BRoV} \mathrm{A}$, and $\mathrm{BCoV}$, source of the calves, FTPI status, BW on arrival, and arrival group were offered to the generalized linear model evaluating the presence of severe diarrhea (fecal score of 3 ) and the cumulative test results over the 3 sampling points. In the final model, $\mathrm{BW}$ on arrival and test results for C. parvum, $\mathrm{BRoV} \mathrm{A}$, and $\mathrm{BCoV}$ were included. Similar to previous models, the higher the arrival weight, the lower proportion of days with a fecal score of 3 . Calves that tested positive for $C$. parvum had a higher proportion of days with a fecal score of 3 than calves that tested negative at the 3 sampling points. We observed similar findings for calves that tested positive for $\mathrm{BCoV}$ and $\mathrm{BRoV}$ A. However, we found an interaction between $\mathrm{BCoV}$ and $\mathrm{BRoV} \mathrm{A}$ : calves that tested positive for both infections had a higher proportion of days with a fecal score of 3 (14.1 \pm $13.4 \%)$ than those that tested negative for both $(4.0 \pm$ $1.0 \%)$ or positive for only $\mathrm{BCoV}(7.4 \pm 5.0 \%)$ or $\mathrm{BRoV}$ A $(8.7 \pm 7.2 \%$; Table 2$)$.

\section{Treatment for Respiratory Disease}

Similar to treatment for diarrhea, the majority of calves were treated for respiratory disease (171/198; $86 \%$; Figure $4 \mathrm{~b}$ ). When we evaluated the effect of testing positive at specific time points, we offered source of the calves, BW on arrival, and test results for BRoV $\mathrm{A}$ and $C$. parvum on arrival to a multivariable Cox proportional hazards model, but retained only BW on arrival and source of the calves. Calves that weighed 44.5 to $47.0 \mathrm{~kg}$ (HR $0.60,95 \%$ CI 0.38 to $0.94 ; P=$ 0.03 ) and 47.0 to $49.4 \mathrm{~kg}$ (HR $0.60,95 \%$ CI 0.37 to $0.96 ; P=0.03)$ on arrival were less likely to be treated for respiratory disease than calves that weighed less than $44.5 \mathrm{~kg}$ on arrival. Calves from drover 2 had a
A.

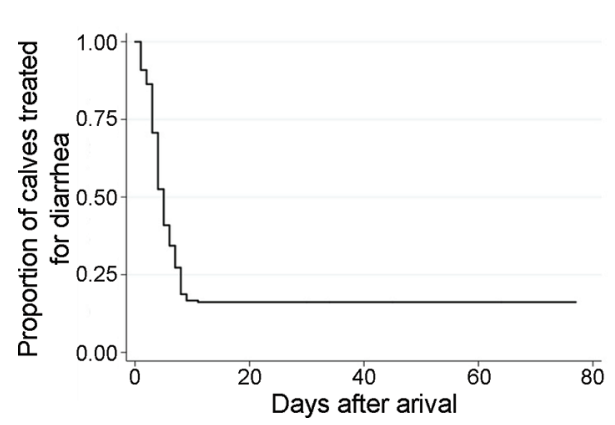

B.

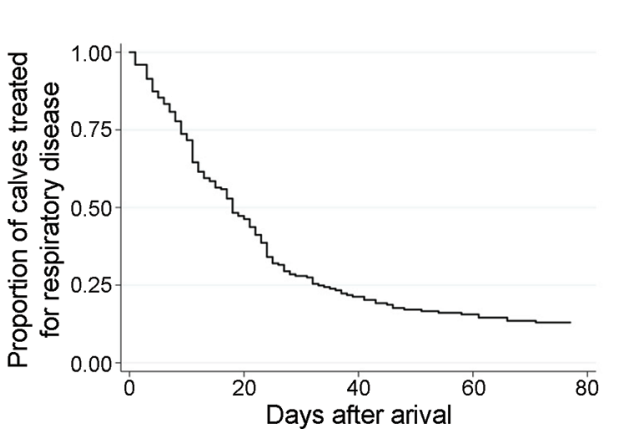

C.

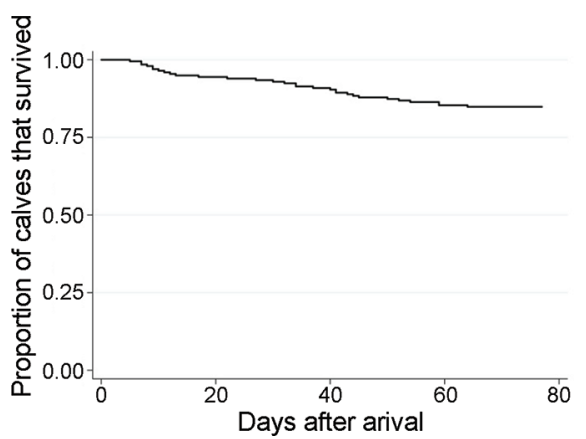

Figure 4. Kaplan-Meier survival curves for (A) treatment for diarrhea, (B) treatment for respiratory disease, and (C) mortality for 198 male dairy calves housed at a grain-fed veal facility. 
Table 1. Results from a generalized linear model evaluating factors associated with the proportion of days with a fecal score of 3 when evaluating pathogen test results at each time point ${ }^{1}$

\begin{tabular}{lcccc}
\hline Variable & Coefficient & $\begin{array}{c}\text { Relative } \\
\text { proportion ratio }\end{array}$ & $95 \%$ CI & $P$-value \\
\hline $\begin{array}{l}\text { Arrival weight } \\
\text { Every 1-kg increase }\end{array}$ & -0.06 & 0.95 & 0.91 to 0.99 & 0.01 \\
$\begin{array}{l}\text { Source of calves } \\
\text { Local dairy farms }\end{array}$ & Referent & & & \\
Drover 1 & 0.37 & 1.44 & 0.92 to 2.29 & 0.11 \\
Drover 2 & 0.59 & 1.80 & 1.24 to 2.60 & 0.002 \\
Constant & 0.43 & 1.54 & 0.20 to 12.1 & 0.68 \\
\hline
\end{tabular}

${ }^{1}$ From 198 male Holstein calves housed at a grain-fed veal facility.

higher risk of being treated for respiratory disease (HR $1.62,95 \%$ CI 1.08 to $2.43 ; P=0.02$ ) than calves from local dairy farms.

Evaluating the test results cumulatively, we offered the source of the calves, BW on arrival, and cumulative test results for C. parvum to the Cox proportional hazards model, and each variable was retained in the final model. Calves that tested positive for C. parvum at any sampling point had a higher hazard of being treated for respiratory disease (HR 1.44, 95\% CI 1.02 to $2.04 ; P$ $=0.04$ ) than calves that tested negative for $C$. parvum at all 3 time points. With respect to $\mathrm{BW}$ on arrival, calves that weighed 44.5 to $47.0 \mathrm{~kg}$ had a lower hazard of treatment for respiratory disease (HR 0.60, 95\% CI 0.37 to $0.98 ; P=0.04$ ) than calves that weighed less than $44.5 \mathrm{~kg}$. Calves from drover 2 also had a higher hazard of treatment for respiratory disease (HR 1.63, 95\% CI 1.06 to $2.52 ; P=0.03)$ than calves from local dairy farms.

\section{Mortality}

A total of 30 calves (15\%) died during this study (Figure $4 \mathrm{c})$. The mean $( \pm \mathrm{SD})$ number of days from ar- rival until death was $30.5 \pm 18.5 \mathrm{~d}$; $60 \%$ died as a result of pneumonia, and $40 \%$ died because of dehydration as a result of diarrhea. Because of this unexpectedly high level of mortality, we conducted additional testing on calves that died from respiratory disease and confirmed an outbreak of Salmonella Dublin based on bacteriology.

We found no differences in Cox proportional hazards models between calves that tested positive for any of the pathogens at the specific sampling time points or when evaluated cumulatively. The $\mathrm{BCoV}$ test results at $7 \mathrm{~d}$ after arrival were offered to the multivariable model, along with BW on arrival and source of the calves, but it was not retained. Only the source of the calves remained in the final model: calves from drover 2 had a higher hazard of mortality (HR 2.44, 95\% CI $1.03-5.80 ; P=0.04)$ than calves from local dairy farms.

\section{Growth}

Calves' BW (mean \pm SD) at 14, 49, 56, and 77 $\mathrm{d}$ were $50.73 \pm 4.61 \mathrm{~kg}, 73.90 \pm 11.81 \mathrm{~kg}, 79.33 \pm$ $13.16 \mathrm{~kg}$, and $98.76 \pm 19.73 \mathrm{~kg}$, respectively. The first repeated-measures linear regression model evaluated

Table 2. Results from a generalized linear model evaluating factors associated with the proportion of days with a fecal score of 3 when evaluating cumulative test results over all sampling time points ${ }^{1}$

\begin{tabular}{|c|c|c|c|c|}
\hline Variable & Coefficient & $\begin{array}{c}\text { Relative } \\
\text { proportion ratio }\end{array}$ & $95 \%$ CI & $P$-value \\
\hline \multicolumn{5}{|l|}{ Arrival weight } \\
\hline Every 1-kg increase & -0.05 & 0.95 & 0.92 to 0.98 & 0.004 \\
\hline Negative at each time point & Referent & & & \\
\hline Positive & 1.05 & 2.85 & 1.99 to 4.08 & $<0.001$ \\
\hline \multicolumn{5}{|l|}{ Bovine rotavirus A } \\
\hline \multicolumn{5}{|l|}{ Cryptosporidium parvum } \\
\hline Negative at each time point & Referent & & & \\
\hline Positive & 0.32 & 1.38 & 1.01 to 1.87 & 0.04 \\
\hline Constant & -1.35 & 0.26 & 0.06 to 1.13 & 0.07 \\
\hline
\end{tabular}

${ }^{1}$ From 198 male Holstein calves housed at a grain-fed veal facility. 

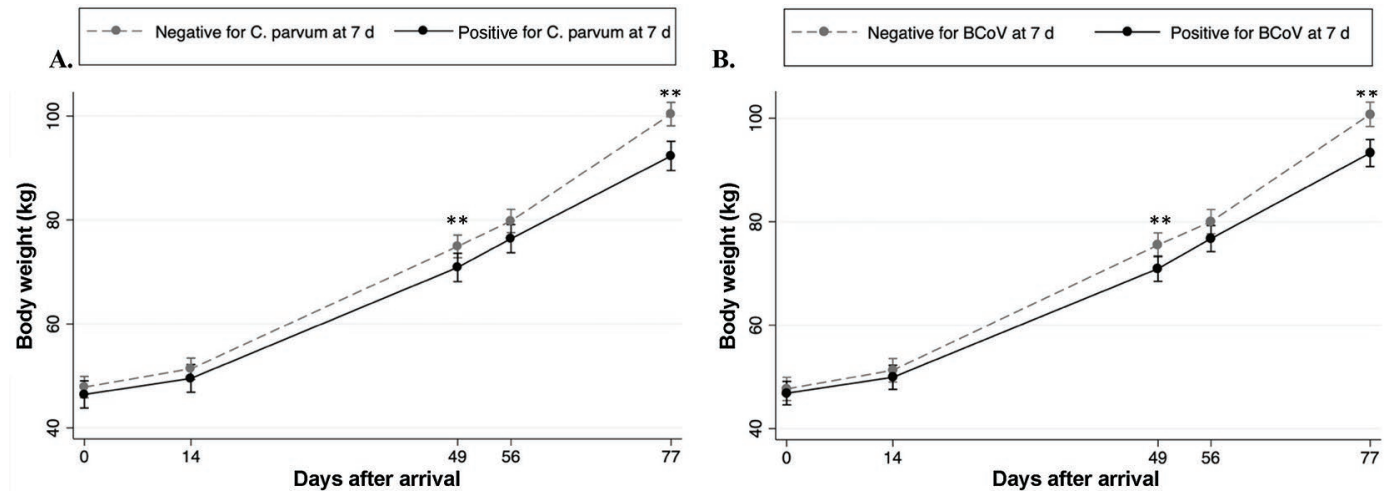

Figure 5. Predicted margin results from a mixed repeated-measures model evaluating the effect of (A) Cryptosporidium parvum and (B) bovine coronavirus $(\mathrm{BCoV})$ infection on $\mathrm{BW}$ gain of 198 male dairy calves at $7 \mathrm{~d}$ after arrival at a grain-fed veal facility. ${ }^{* *}$ Significant finding $(P<0.05)$ between those that tested positive those that tested negative for the respective pathogen at $7 \mathrm{~d}$.

the test results at individual time points and found that test results for $\mathrm{BCoV}$ and C. parvum on arrival and at $7 \mathrm{~d}$ and the source of the calves were significant in univariable regression. In the final model, $\mathrm{BCoV}$ and C. parvum results at $7 \mathrm{~d}$ were retained, and we found an interaction with the day BW was measured for both variables. Calves that tested positive for $C$. parvum at $7 \mathrm{~d}$ had lower BW at $49 \mathrm{~d}(-4.05 \mathrm{~kg}, 95 \% \mathrm{CI}-0.56$ to $-7.55 ; P=0.02)$ and $77 \mathrm{~d}(-8.06 \mathrm{~kg}, 95 \% \mathrm{CI}-4.45$ to -11.67; $P<0.001 ;$ Figure 5a) than calves that tested negative for $C$. parvum at $7 \mathrm{~d}$. Calves that tested positive for $\mathrm{BCoV}$ at $7 \mathrm{~d}$ had lower $\mathrm{BW}$ at $49 \mathrm{~d}(-4.57 \mathrm{~kg}$, $95 \% \mathrm{CI}-1.19$ to $-7.96 ; P=0.008)$ and $77 \mathrm{~d}(-7.48 \mathrm{~kg}$, 95\% CI -3.97 to $-10.98 ; P<0.001$; Figure $5 \mathrm{~b}$ ) than those that tested negative for $\mathrm{BCoV}$ at $7 \mathrm{~d}$.

In the repeated-measures linear regression model evaluating the cumulative test results, source of the calves and cumulative test results for $\mathrm{BCoV}$, C. par- vum, and BRoV A were offered to the multivariable model. Only the cumulative test results for $C$. parvum and $\mathrm{BCoV}$ were retained, and both variables had an interaction term with the day BW was measured. Calves that tested positive for C. parvum at any time point had a lower BW at $49 \mathrm{~d}(-3.81 \mathrm{~kg}, 95 \% \mathrm{CI}-0.17$ to $-7.45 ; P=0.04), 56 \mathrm{~d}(-4.20 \mathrm{~kg}, 95 \% \mathrm{CI}-0.50$ to $-7.89 ; P=0.03)$, and $77 \mathrm{~d}(-6.03 \mathrm{~kg}, 95 \% \mathrm{CI}-2.29$ to $-9.77 ; P=0.002)$ than calves that tested negative at each sampling point (Figure 6a). Similarly, calves that tested positive for $\mathrm{BCoV}$ had a lower $\mathrm{BW}$ at 56 $\mathrm{d}(-5.44 \mathrm{~kg}, 95 \% \mathrm{CI}-0.55$ to $-10.32 ; P=0.03)$ and $77 \mathrm{~d}(-7.06 \mathrm{~kg}, 95 \% \mathrm{CI}-2.16$ to $-11.97 ; P=0.005$; Figure $6 \mathrm{~b})$.

We completed 2 repeated-measures analyses with respect to growth and the proportion of days with diarrhea or severe diarrhea. The first model evaluating the effect of diarrhea on growth found that as the propor-
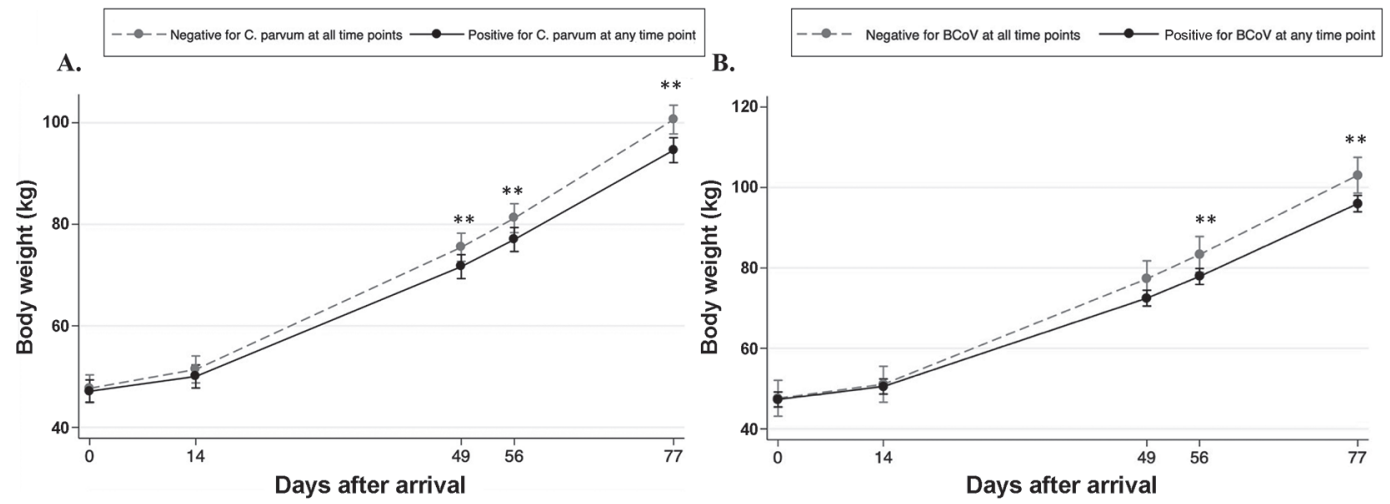

Figure 6. Predicted margin results from a mixed repeated-measures model evaluating the effect of testing positive for (A) Cryptosporidium parvum and $(\mathrm{B})$ bovine coronavirus $(\mathrm{BCoV})$ at any sampling time point after arrival on the growth of 198 male dairy calves housed at a grainfed veal facility. ${ }^{*}$ Significant finding $(P<0.05)$ between those that tested positive for the respective pathogen at any time point and those that tested negative at each time point. 
Table 3. Predicted margins from a repeated-measures linear regression model comparing the weight loss between differing levels of a proportion of days with diarrhea to a baseline of $<25 \%$ of days in the first $28 \mathrm{~d}$ with diarrhea ${ }^{1}$

\begin{tabular}{|c|c|c|c|}
\hline $\begin{array}{l}\text { Proportion of first } 28 \mathrm{~d} \text { with diarrhea } \\
\text { (fecal score } 2 \text { or } 3 \text { ) and day }\end{array}$ & $\begin{array}{l}\text { Predicted weight } \\
\text { difference }(\mathrm{kg})\end{array}$ & $95 \% \mathrm{CI}$ & $P$-value \\
\hline \multicolumn{4}{|l|}{$<25 \%$ to $25-30 \%$} \\
\hline 14 & -2.12 & -6.67 to 2.43 & 0.36 \\
\hline 49 & -6.64 & -11.42 to -1.87 & 0.006 \\
\hline 56 & -5.01 & -9.80 to -0.22 & 0.04 \\
\hline 77 & -6.24 & -11.07 to -1.40 & 0.01 \\
\hline \multicolumn{4}{|l|}{$<25 \%$ to $30-38 \%$} \\
\hline 14 & -2.82 & -7.35 to 1.73 & 0.23 \\
\hline 49 & -7.92 & -12.69 to -3.15 & 0.001 \\
\hline 56 & -8.15 & -12.94 to -3.36 & 0.001 \\
\hline \multirow{2}{*}{\multicolumn{4}{|c|}{$<25 \%$ to $>38 \%$}} \\
\hline & & & \\
\hline 14 & -4.21 & -8.74 to 0.32 & 0.07 \\
\hline 49 & -11.88 & -16.72 to -7.04 & $<0.001$ \\
\hline 56 & -9.39 & -14.29 to -4.49 & $<0.001$ \\
\hline 77 & -15.60 & -20.57 to -10.63 & $<0.001$ \\
\hline
\end{tabular}

${ }^{1}$ From 198 male Holstein calves housed at a grain-fed veal facility.

tion of days with diarrhea increased, calf BW decreased. Specifically, calves that spent less than $25 \%$ of the first $28 \mathrm{~d}$ with diarrhea had a higher BW at 49,56 , and $77 \mathrm{~d}$ than calves that spent 25 to $30 \%, 30$ to $38 \%$, and more than $38 \%$ of the first $28 \mathrm{~d}$ with a diarrhea (Table 3 ). We found similar results for severe diarrhea: a higher proportion of days with severe diarrhea led to a greater loss in BW. Calves that spent less than $4 \%$ of the first $28 \mathrm{~d}$ with a fecal score of 3 had a higher BW at 14, 49, 56 , and $77 \mathrm{~d}$ than calves that spent more than $16 \%$ of the first $28 \mathrm{~d}$ with a fecal score of 3 . Calves that spent 4 to $11 \%$ and 11 to $16 \%$ of the first $28 \mathrm{~d}$ with severe diarrhea had a lower BW than calves that spent less than $4 \%$ of the first $28 \mathrm{~d}$ with severe diarrhea (Table 4 ).

\section{DISCUSSION}

This study identified high levels of $\mathrm{BCoV}, \mathrm{BRoV}$ A, and C. parvum infection in male dairy calves in our study population. We also demonstrated that an infection with 1 of the pathogens or coinfection with $\mathrm{BCoV}$ and $\mathrm{BRoV} \mathrm{A}$ was associated with higher levels of diarrhea. Infection with $\mathrm{BCoV}$ and $C$. parvum was associated with a reduction in growth over the period of observation. The source of the arriving calves and level of STP measured on arrival were also factors that contributed to infection with 1 of the pathogens. When interpreting the results of this study, a major limitation to consider is the high burden of disease and mortality

Table 4. Predicted margins from a repeated-measures linear regression model comparing the weight loss between differing levels of a proportion of days with severe diarrhea to a baseline of $<4 \%$ of days in the first $28 \mathrm{~d}$ with diarrhea ${ }^{1}$

\begin{tabular}{lccc}
\hline $\begin{array}{l}\text { Proportion of first 28 d with severe } \\
\text { diarrhea (fecal score 3) and day }\end{array}$ & $\begin{array}{c}\text { Predicted weight } \\
\text { difference (kg) }\end{array}$ & $95 \%$ CI & $P$-value \\
\hline$<4 \%$ to $4-11 \%$ & & -6.27 to 2.89 & 0.47 \\
14 & -1.69 & -9.91 to -0.15 & 0.04 \\
49 & -5.03 & -12.58 to -2.78 & 0.002 \\
56 & -7.68 & -11.67 to -1.82 & 0.007 \\
77 & -6.74 & & \\
$<4 \%$ to $11-16 \%$ & -2.51 & -7.47 to 2.45 & 0.32 \\
14 & -5.88 & -11.11 to -1.03 & 0.02 \\
49 & -6.27 & -11.51 to -1.03 & 0.02 \\
56 & -12.63 & -17.91 to -7.35 & $<0.001$ \\
77 & & & \\
14 & -4.80 & -9.60 to -0.001 & 0.05 \\
49 & -11.04 & -16.17 to -5.91 & $<0.001$ \\
56 & -11.05 & -16.23 to -5.86 & $<0.001$ \\
77 & -16.13 & -21.38 to -10.88 & $<0.001$ \\
\hline
\end{tabular}

${ }^{1}$ From 198 male Holstein calves housed at a grain-fed veal facility. 
that occurred over the experiment. The levels that occurred during the study period were much higher than previously reported in other studies examining male dairy calves (Renaud et al., 2018b; Scott et al., 2019), and was the result of an outbreak of Salmonella Dublin. This outbreak likely affected some of our results (specifically for growth) because of the number of calves lost, and it may also have affected associations between specific pathogens and the outcomes measured. An additional limitation is that we did not measure bacterial pathogens responsible for causing diarrhea. Because of budgetary limitations and the likelihood of a low prevalence of bacterial pathogens, we did not test for bacteria. Nonetheless, we feel that this study sheds some light on the high burden of viral and parasitic infections in calves and the specific consequences of infection. A final limitation to consider is that freezing the fecal samples may have affected the microscopic stains for detecting C. parvum oocysts; however, Brook et al. (2008) found identical performance using microscopy to identify C. parvum oocysts in fresh and frozen feces.

The reported detection rates from this study clearly highlight a high rate of infection. With respect to $\mathrm{BCoV}$, the level ( $86 \%$ positive over 3 time points) was higher than previous reports, which reported $\mathrm{BCoV}$ levels of 8 to $22 \%$ (Lanz Uhde et al., 2008; Izzo et al., 2011). However, more recent studies have identified a prevalence of 55 to $79 \%$ in dairy calves (Lojkić et al., 2015; Gomez et al., 2017). Levels of BRoV A infection were also much higher than previous reports, with $94 \%$ of calves testing positive at least once. Specifically, BRoV was identified in 59 to $80 \%$ of dairy calves with diarrhea (Lanz Uhde et al., 2008; Izzo et al., 2011; Gomez and Weese, 2017). Variable levels of C. parvum infection have been identified in previous studies, with prevalences between 3 and 97\% (Thomson et al., 2017; Urie et al., 2018). In our study, $57 \%$ of calves tested positive for C. parvum over the sampling time points. The higher levels of viral infection reported in this study likely reflected the number of sampling time points used compared with previous studies, which sampled at only 1 time point. In future studies, additional sampling time points may be necessary to identify calves that are infected to truly understand the level of infection and the effect of each pathogen.

Characteristics of the arriving calves were associated with the isolation of 1 of the pathogens from their feces. The source of the calves played a role: calves sourced from a specific drover had higher levels of each pathogen. Previous research has identified that specific dairy herd management practices are associated with C. parvum, such as larger herd size, warmer environmental temperature, the use of prophylaxis in cows and calves to prevent diarrhea, feeding milk replacer, using concrete flooring in calf housing, and the use of soap or detergent when washing calf feeding utensils (Trotz-Williams et al., 2008; Urie et al., 2018). The higher levels of infections in calves from drover 2 could also be explained by the longer distance traveled or by commingling in transit. A higher level of STP was also associated with lower levels of $\mathrm{BCoV}$ infection in this study. Previous research has shown similar findings, where calves with lower levels of passive immunity were at higher risk of enteric infection (Lora et al., 2018). The findings from this study further highlight the importance of male calf colostrum management at the source dairy farms, because this could have a significant effect on risk of infection.

Infection with 1 of the identified enteric pathogens had a number of consequences. All of the pathogens we investigated were associated with a higher risk of severe diarrhea, and C. parvum was associated with an increased risk of diarrhea. These findings aligned with the literature, where infection with each pathogen led to higher levels of diarrhea (Trotz-Williams et al., 2007; Cho et al., 2013; Gomez et al., 2017). Interestingly, the sole interaction observed between the pathogens was when both $\mathrm{BCoV}$ and $\mathrm{BRoV}$ A were present, increasing the proportion of days with severe diarrhea. This type of interaction has not been well described; however, others have identified interactions between BRoV and C. parvum (Bartels et al., 2010). Given the welfare implications associated with diarrhea, targeted approaches to reduce the effect of these pathogens is necessary through improved colostrum management at source dairy farms and nutrition at calf raising facilities (Trotz-Williams et al., 2007; Ollivett et al., 2012).

This studied found that as the proportion of days calves spent with either diarrhea or severe diarrhea increased, their BW gain was adversely affected. We found more than a $15 \mathrm{~kg}$ difference at $77 \mathrm{~d}$ in calves with high levels of diarrhea compared to those with low levels of diarrhea. Previous studies have identified this association between the presence of diarrhea and reduced growth (Pardon et al., 2013; Windeyer et al., 2014), but few have identified the specific effect of an infection. This study highlighted the reduced growth associated with a C. parvum and $\mathrm{BCoV}$ infection, and the increased risk of respiratory disease associated with a C. parvum infection. A recent paper identified the effect of $C$. parvum on long-term weight reduction (Shaw et al., 2020), but no studies have specifically identified $\mathrm{BCoV}$ as having an effect on the growth of dairy calves. This reduction in growth was likely due to damage to enterocytes, leading to villous atrophy and ultimately malabsorption of nutrients (Cho and Yoon, 2014). The association of diarrhea and respiratory disease has been previously identified (Curtis et al., 1988; Svensson et 
al., 2006), but the association of $C$. parvum with respiratory disease has not been described. It likely that infection with $C$. parvum leads to diarrhea, which causes immunosuppression, contributing to an increased risk of respiratory disease. Given the high burden of respiratory disease in dairy calves (Windeyer et al., 2014) and the consequences for future growth (Pardon et al., 2013) and milk production in females (Dunn et al., 2018), more research is needed to confirm this association and describe the reason for its occurrence.

\section{CONCLUSIONS}

This study demonstrated that the prevalence of $\mathrm{BCoV}, \mathrm{BRoV} \mathrm{A}$, and C. parvum infection was high in male dairy calves and had significant effects on the occurrence of diarrhea, respiratory disease, and BW gain. Future studies should evaluate approaches such as improved management or nutrition to minimize the effect of infection with these pathogens and improve animal welfare, health, and productivity.

\section{ACKNOWLEDGMENTS}

The authors thank the Canadian Agricultural Partnership (Ottawa, ON, Canada) for funding this research. We also thank the calf facility for participating in this research. The authors have no conflicts of interest to declare.

\section{REFERENCES}

Bartels, C. J. M., M. Holzhauer, R. Jorritsma, W. A. J. M. Swart, and T. J. G. M. Lam. 2010. Prevalence, prediction and risk factors of enteropathogens in normal and non-normal faeces of young Dutch dairy calves. Prev. Vet. Med. 93:162-169. https://doi.org/10.1016/ j.prevetmed.2009.09.020.

Brook, E. J., R. M. Christley, N. P. French, and C. A. Hart. 2008. Detection of Cryptosporidium oocysts in fresh and frozen cattle faeces: Comparison of three methods. Lett. Appl. Microbiol. 46:26-31.

Cho, Y.-I., J.-I. Han, C. Wang, V. Cooper, K. Schwartz, T. Engelken, and K.-J. Yoon. 2013. Case-control study of microbiological etiology associated with calf diarrhea. Vet. Microbiol. 166:375-385. https://doi.org/10.1016/j.vetmic.2013.07.001.

Cho, Y.-I., and K.-J. Yoon. 2014. An overview of calf diarrhea-Infectious etiology, diagnosis, and intervention. J. Vet. Sci. 15:1-17. https://doi.org/10.4142/jvs.2014.15.1.1.

Curtis, C. R., H. N. Erb, and M. E. White. 1988. Descriptive epidemiology of calfhood morbidity and mortality in New York Holstein herds. Prev. Vet. Med. 5:293-307. https://doi.org/10.1016/0167 $-5877(88) 90015-3$.

Dohoo, I., W. Martin, and H. Stryhn. 2010. Model-building strategies. Pages 365-394 in Veterinary Epidemiological Research. 2nd ed. University of Prince Edward Island, Charlottetown, Canada.

Dunn, T. R., T. L. Ollivett, D. L. Renaud, K. E. Leslie, S. J. LeBlanc, T. F. Duffield, and D. F. Kelton. 2018. The effect of lung consolidation, as determined by ultrasonography, on first-lactation milk production in Holstein dairy calves. J. Dairy Sci. 101:5404-5410. https://doi.org/10.3168/jds.2017-13870.

Gomez, D. E., L. G. Arroyo, Z. Poljak, L. Viel, and J. S. Weese. 2017. Detection of bovine coronavirus in healthy and diarrheic dairy calves. J. Vet. Intern. Med. 31:1884-1891. https://doi.org/ 10.1111/jvim.14811.

Gomez, D. E., and J. S. Weese. 2017. Viral enteritis in calves. Can. Vet. J. 58:1267-1274.

Izzo, M. M., P. D. Kirkland, V. L. Mohler, N. R. Perkins, A. A. Gunn, and J. K. House. 2011. Prevalence of major enteric pathogens in Australian dairy calves with diarrhoea. Aust. Vet. J. 89:167-173.

Kaneene, J. B., and H. S. Hurd. 1990. The National Animal Health Monitoring System in Michigan. III. Cost estimates of selected dairy cattle diseases. Prev. Vet. Med. 8:127-140. https://doi.org/ 10.1016/0167-5877(90)90006-4.

Lojkić, I., N. Krešić, I. Šimić, and T. Bedeković. 2015. Detection and molecular characterization of bovine corona and toroviruses from Croatian cattle. BMC Vet. Res. 11:202-207. https://doi.org/10 $.1186 / \mathrm{s} 12917-015-0511-9$.

Lora, I., F. Gottardo, B. Contiero, B. Dall Ava, L. Bonfanti, A. Stefani, and A. Barberio. 2018. Association between passive immunity and health status of dairy calves under 30 days of age. Prev. Vet. Med. 152:12-15. https://doi.org/10.1016/j.prevetmed.2018.01.009.

Love, W. J., T. W. Lehenbauer, P. H. Kass, A. L. Van Eenennaam, and S. S. Aly. 2014. Development of a novel clinical scoring system for on-farm diagnosis of bovine respiratory disease in pre-weaned dairy calves. PeerJ 2:e238. https://doi.org/10.7717/peerj.238.

McGuirk, S. M. 2008. Disease management of dairy calves and heifers. Vet. Clin. North Am. Food Anim. Pract. 24:139-153. https://doi .org/10.1016/j.cvfa.2007.10.003.

Nydam, D. V., and H. O. Mohammed. 2005. Quantitative risk assessment of Cryptosporidium species infection in dairy calves. J. Dairy Sci. 88:3932-3943. https://doi.org/10.3168/jds.S0022 -0302(05)73079-4.

Ollivett, T. L., D. V. Nydam, T. C. Linden, D. D. Bowman, and M. E. Van Amburgh. 2012. Effect of nutritional plane on health and performance in dairy calves after experimental infection with Cryptosporidium parvum. J. Am. Vet. Med. Assoc. 241:1514-1520. https://doi.org/10.2460/javma.241.11.1514.

Papp, H., B. László, F. Jakab, B. Ganesh, S. De Grazia, J. Matthijnssens, M. Ciarlet, V. Martella, and K. Bányai. 2013. Review of group A rotavirus strains reported in swine and cattle. Vet. Microbiol. 165:190-199. https://doi.org/10.1016/j.vetmic.2013.03.020.

Pardon, B., M. Hostens, L. Duchateau, J. Dewulf, K. De Bleecker, and P. Deprez. 2013. Impact of respiratory disease, diarrhea, otitis and arthritis on mortality and carcass traits in white veal calves. BMC Vet. Res. 9:79. https://doi.org/10.1186/1746-6148-9-79.

Renaud, D. L., T. F. Duffield, S. J. LeBlanc, and D. F. Kelton. 2018a. Short communication: Validation of methods for practically evaluating failed passive transfer of immunity in calves arriving at a veal facility. J. Dairy Sci. 101:9516-9520. https://doi.org/10.3168/ jds.2018-14723.

Renaud, D. L., D. F. Kelton, S. J. LeBlanc, D. B. Haley, and T. F. Duffield. 2018b. Calf management risk factors on dairy farms associated with male calf mortality on veal farms. J. Dairy Sci. 101:1785-1794. https://doi.org/10.3168/jds.2017-13578.

Roche, S. M., M. Von Massow, D. Renaud, D. A. Shock, A. JonesBitton, and D. F. Kelton. 2020. Cost-benefit of implementing a participatory extension model for improving on-farm adoption of Johne's disease control recommendations. J. Dairy Sci. 103:451472. https://doi.org/10.3168/jds.2019-16708.

Scott, K., D. F. Kelton, T. F. Duffield, and D. L. Renaud. 2019. Risk factors identified on arrival associated with morbidity and mortality at a grain-fed veal facility: A prospective, single-cohort study. J. Dairy Sci. 102:9224-9235. https://doi.org/10.3168/jds.2019-16829.

Shaw, H. J., E. A. Innes, L. J. Morrison, F. Katzer, and B. Wells. 2020. Long-term production effects of clinical cryptosporidiosis in neonatal calves. Int. J. Parasitol. 50:371-376. https://doi.org/10 .1016/j.ijpara.2020.03.002.

Svensson, C., and J. Hultgren. 2008. Associations between housing, management, and morbidity during rearing and subsequent first lactation milk production of dairy cows in southwest Sweden. J. Dairy Sci. 91:1510-1518. https://doi.org/10.3168/jds.2007-0235.

Svensson, C., J. Hultgren, and P. A. Oltenacu. 2006. Morbidity in 3-7 month-old dairy calves in south-western Sweden, and risk factors 
for diarrhoea and respiratory disease. Prev. Vet. Med. 74:162-179. https://doi.org/10.1016/j.prevetmed.2005.11.008.

Thomson, S., C. A. Hamilton, J. C. Hope, F. Katzer, N. A. Mabbott, L. J. Morrison, and E. A. Innes. 2017. Bovine cryptosporidiosis: Impact, host-parasite interaction and control strategies. Vet. Res. 48:42. https://doi.org/10.1186/s13567-017-0447-0.

Trotz-Williams, L. A., S. W. Martin, K. E. Leslie, T. Duffield, D. V. Nydam, and A. S. Peregrine. 2007. Calf-level risk factors for neonatal diarrhea and shedding of Cryptosporidium parvum in Ontario dairy calves. Prev. Vet. Med. 82:12-28. https://doi.org/10.1016/j .prevetmed.2007.05.003.

Trotz-Williams, L. A., S. W. Martin, K. E. Leslie, T. Duffield, D. V. Nydam, and A. S. Peregrine. 2008. Association between management practices and within-herd prevalence of Cryptosporidium parvum shedding on dairy farms in southern Ontario. Prev. Vet. Med. 83:11-23. https://doi.org/10.1016/j.prevetmed.2007.03.001.

Lanz Uhde, F., T. Kaufmann, H. Sager, S. Albini, R. Zanoni, E. Schelling, and M. Meylan. 2008. Prevalence of four enteropathogens in the faeces of young diarrhoeic dairy calves in Switzerland. Vet. Rec. 163:362-366. https://doi.org/10.1136/vr.163.12.362.

Urie, N. J., J. E. Lombard, C. B. Shivley, A. E. Adams, C. A. Kopral, and M. Santin. 2018. Preweaned heifer management on US dairy operations: Part III. Factors associated with Cryptosporidium and
Giardia in preweaned dairy heifer calves. J. Dairy Sci. 101:91999213. https://doi.org/10.3168/jds.2017-14060.

Waltner-Toews, D., S. W. Martin, and A. H. Meek. 1986b. An epidemiological study of selected calf pathogens on Holstein dairy farms in southwestern Ontario. Can. J. Vet. Res. 50:307-313.

Waltner-Toews, D., S. W. Martin, A. H. Meek, and I. McMillan. 1986a. Dairy calf management, morbidity and mortality in Ontario Holstein herds. I. The data. Prev. Vet. Med. 4:103-124. https://doi .org/10.1016/0167-5877(86)90017-6.

Windeyer, M. C., K. E. Leslie, S. M. Godden, D. C. Hodgins, K. D. Lissemore, and S. J. LeBlanc. 2014. Factors associated with morbidity, mortality, and growth of dairy heifer calves up to 3 months of age. Prev. Vet. Med. 113:231-240. https://doi.org/10.1016/j .prevetmed.2013.10.019.

\section{ORCIDS}

D. L. Renaud (ㄴ) https://orcid.org/0000-0002-3439-3987

C. Rot ๑ https://orcid.org/0000-0003-2099-5159

J. Marshall (® https://orcid.org/0000-0002-0235-2224

M. A. Steele ๑ https://orcid.org/0000-0001-6941-6205 